\title{
Culture-dependent and culture-independent diversity surveys target different bacteria: a case study in a freshwater sample
}

\author{
Ivone Vaz-Moreira • Conceição Egas • \\ Olga C. Nunes · Célia M. Manaia
}

\begin{abstract}
Compared with culture-independent approaches, traditionally used culture-dependent methods have a limited capacity to characterize water microbiota. Nevertheless, for almost a century the latter have been optimized to detect and quantify relevant bacteria. A pertinent question is if culture-independent diversity surveys give merely an extended perspective of the bacterial diversity or if, even with a higher coverage, focus on a different set of organisms. We compared the diversity and phylogeny of bacteria in a freshwater sample recovered by currently used culture-dependent and culture-independent methods (DGGE and 454 pyrosequencing). The culture-dependent diversity
\end{abstract}

I. Vaz-Moreira · C. M. Manaia ( $₫)$

CBQF/Escola Superior de Biotecnologia, Universidade

Católica Portuguesa, R. Dr. António Bernardino de

Almeida, 4200-072 Porto, Portugal

e-mail: cmmanaia@esb.ucp.pt

I. Vaz-Moreira · O. C. Nunes

LEPAE-Departamento de Engenharia Química,

Faculdade de Engenharia, Universidade do Porto,

4200-465 Porto, Portugal

C. Egas

Advanced Services Unit, Biocant, 3060-197 Cantanhede,

Portugal

C. Egas

Center for Neurosciences and Cellular Biology,

University of Coimbra, 3004-517 Coimbra, Portugal survey presented lower coverage than the other methods. However, it allowed bacterial identifications to the species level, in contrast with the other procedures that rarely produced identifications below the order. Although the predominant bacterial phyla detected by both approaches were the same (Proteobacteria, Actinobacteria, Bacteroidetes), sequence similarity analysis showed that, in general, different operational taxonomical units were targeted by each method. The observation that culture-dependent and independent approaches target different organisms has implications for the use of the latter for studies in which taxonomic identification has a predictive value. In comparison to DGGE, 454 pyrosequencing method had a higher capacity to explore the bacterial richness and to detect cultured organisms, being also less laborious.

Keywords Culture-dependent - Cultureindependent · DGGE · 454 Pyrosequencing · Freshwater - Bacterial diversity

\section{Introduction}

Bacterial diversity surveys of natural waters are important approaches to assess the ecology and evolution of bacteria, to support management policies or to sustain risk assessment studies. For almost a century, the microbiological quality of waters was 
based on culture-dependent methods, which have been continuously optimized to detect and quantify the presence of organisms relevant in terms of quality control, public health or risk assessment studies (e.g. Leclerc 1994; Leclerc and Moreau 2002; Mossel and Struijk 2004). The culture-independent methods revealed the immense diversity of uncultured organisms, and thus, highlighted the need to implement complementary approaches for the analysis of water bacterial diversity (Amann et al. 1995; Palleroni 1997; Hugenholtz 2002; Kemp and Aller 2004; Venter et al. 2004; Alain and Querellou 2009). Several scientific and technological developments, but above all, the inexpensiveness of the nucleic acids sequencing methods, brought obvious improvements to bacterial diversity studies. The use of methods such as 16S rRNA gene clone libraries, fluorescence in situ hybridization (FISH) or denaturing gradient gel electrophoresis (DGGE) are nowadays a common place, and their use to explore the bacterial diversity in waters was exemplified in several publications (Amann et al. 2001; Dewettinck et al. 2001; Zwart et al. 2002; Cottrell et al. 2005; Hoefel et al. 2005; Loy et al. 2005; Bottari et al. 2006; Wu et al. 2006; de Figueiredo et al. 2007; Revetta et al. 2010). More recently, the potential of the high-throughput 454 pyrosequencing to explore the environmental diversity has been emphasized (Roh et al. 2010). In spite of the scientific and technical advances for bacterial diversity surveys, cultivation methods are still of great importance not only for laboratories equipped for routine monitoring, as those responsible for water quality control, but also for making inferences on the physiological and metabolic properties of the organisms (Palleroni 1997; Cardenas and Tiedje 2008). Un-culturability is a broad sense condition that includes: (i) organisms for which the specific growth requirements (nutritional, temperature, aeration, etc.) are not available; (ii) slow-growing organisms, out-competed in the presence of fast-growing microorganisms and (iii) injured organisms, which cannot stand the stressful conditions imposed by cultivation. These categories, which are not necessarily related with specific taxonomic groups, are estimated to represent about 99\% of the environmental bacterial diversity, especially in oligotrophic habitats, as freshwater (Amann et al. 1995; Vartoukian et al. 2010). Based on the analysis of the total DNA of the community, culture- independent methods are supposed to detect a considerable fraction of the uncultivable organisms, eventually in addition to those that can be cultured. Nevertheless it is not self evident that culturedependent and culture-independent methods overlap on the detection of culturable organisms. For studies related with risk assessment and public health issues, as for example, the search of virulence or antibiotic resistance traits, often measured in cultivable organisms, it would be important to use culture-independent approaches in complement of culture-dependent methods, as a way to infer the significance of a specific taxonomic group in the whole community. The current work is integrated in a wider study in which different approaches are being used to assess freshwater bacterial diversity. The work reported herein was designed to assess how the bacterial diversity recovered by traditional culture-dependent methods overlapped with that offered by cultureindependent approaches (DGGE and 454 pyrosequencing). Specifically, it was intended to: (i) compare the range of bacterial groups and precision of the identification level obtained with each method and (ii) assess if the same organism can be targeted by culture-dependent and culture-independent methods.

For the cultivation-dependent approach was used a set of culture media commonly employed in microbiological water analysis (ISO 9308-1:2000; Eaton et al. 2005) and the identification of the isolates was based on the 16S rRNA sequence analysis. Cultureindependent methods included DGGE and 454 pyrosequencing. DGGE based on the analysis of the 16S rRNA gene sequence has become one of the most popular methods to assess bacterial diversity in environmental samples (Muyzer and Smalla 1998; Fromin et al. 2002; Haack et al. 2004; de Figueiredo et al. 2007). Even though, some studies demonstrated that bacterial populations revealed by DGGE can represent less than $1 \%$ of the total community (Muyzer et al. 1993; Murray et al. 1996). The 454 pyrosequencing is a timely DNA sequencing technique that allows the generation of short reads rapidly and inexpensively, with accuracy and avoiding cloning bias (Ronaghi and Elahi 2002; Krause et al. 2008). A recently published study evidences the potential of this high-throughput technique to explore the bacterial richness of biofilms of potable waters (Hong et al. 2010). 


\section{Materials and methods}

Sampling

A surface water sample (5 l) was collected in a river (approximately $3 \mathrm{~m}$ depth) in the area of the water pumping for a drinking water treatment plant (Faria et al. 2009). The sample was collected in a sterile glass flask, transported to the laboratory, and processed within $4 \mathrm{~h}$, as schematized in Fig. 1. The physicochemical and microbiological characteristics of the water sample are indicated in Table 1 .

\section{Microbiological characterization}

Total cell number was determined by fluorescence microscopy after staining with 4',6-diamidino-2phenylindole (DAPI, Sigma-Aldrich, Steinheim, Germany) as described by Brunk et al. (1979). Cell enumerations were made in triplicate as described previously (Manuel et al. 2007; Barreiros et al. 2011).

The diversity of culturable bacteria was surveyed on three culture media commonly used for water microbiological quality control-R2A (Difco, Le Pont de Claix, France), Pseudomonas Isolation Agar (PIA, Difco) and Tergitol 7-Agar (TTC, Oxoid, Hants, UK). Volumes of $1 \mathrm{ml}$ of water or decimal serial dilutions thereof were filtered through cellulose nitrate membranes $(0.45 \mu \mathrm{m}$ pore size, $47 \mathrm{~mm}$ diameter, Albet, Barcelona, Spain), which were placed onto the three different culture media and incubated at $30^{\circ} \mathrm{C}$ (for R2A and PIA) or $37^{\circ} \mathrm{C}$ (for

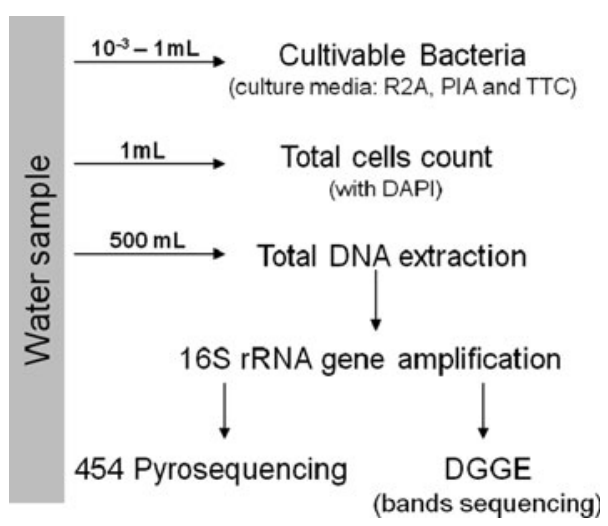

Fig. 1 Schematic representation of the study methodology. For each approach, the sample was processed in triplicate
TTC) up to 7 days. All the process, dilutions and filtrations, was done in triplicate.

\section{Bacterial isolation and characterization}

Bacteria were isolated after the visual examination of the triplicates of culture plates which evidenced a countable number of CFU's. All or half of the colonies were isolated when a morphotype was represented by up to 10 or more CFU's, respectively. The colonies isolated on R2A were purified on the same medium, and those isolated on more nutritive media (PIA or TTC) were purified on PCA (Plate Count Agar, Pronadisa, Madrid, Spain). Pure cultures were preserved at $-80^{\circ} \mathrm{C}$ in nutritive broth supplemented with $15 \%$ (v/v) glycerol. All the isolates were identified on basis of the 16S rRNA gene sequence analysis, using the 27F and 1492R (Lane 1991) as described before (Ferreira da Silva et al. 2007).

\section{Total DNA extraction}

In preliminary assays, two DNA extraction methods were compared-the PowerSoil ${ }^{\mathrm{TM}}$ DNA Isolation kit (MO BIO Laboratories Inc., Carlsbad, CA, USA) and freeze-thawing with liquid nitrogen (Kawai et al. 2002; Hoefel et al. 2005; Wu et al. 2006). The MO BIO kit showed higher efficiency, being selected for further DNA extractions. Four fractions of 0.51 of water sample were filtered through polycarbonate membranes $(0.2 \mu \mathrm{m}$ porosity, Whatman). DNA extraction was made as described by Barreiros et al. (2011), with an additional period of $30 \mathrm{~min}$ of incubation at $65^{\circ} \mathrm{C}$. Four DNA extracts were obtained for further analysis.

DGGE analysis

A 16S rRNA gene fragment of $200 \mathrm{bp}$, corresponding to the region $\mathrm{V} 3$, was amplified with the primers 338F-GC-clamp and 518R (Muyzer et al. 1993). The amplification was performed in a reaction volume of $50 \mu \mathrm{l}$ with $1 \times \mathrm{KCl}$ buffer, $3 \mathrm{mM} \mathrm{MgCl}_{2}, 0.4 \mathrm{mM}$ dNTP's mix, 5\% DMSO, $1 \mu \mathrm{M}$ each primer, $3 \mathrm{U}$ of Taq polymerase (Stabvida, Lisbon, Portugal) and $4 \mu \mathrm{l}$ of template DNA. The PCR conditions were $5 \mathrm{~min}$ at $94^{\circ} \mathrm{C}$, followed by 35 cycles of $30 \mathrm{~s}$ at $94^{\circ} \mathrm{C}, 30 \mathrm{~s}$ at $55^{\circ} \mathrm{C}, 30 \mathrm{~s}$ at $72^{\circ} \mathrm{C}$, and a final extension of $20 \mathrm{~min}$ at $72^{\circ} \mathrm{C}$. The DNA concentration of the PCR products 
Table 1 Physicochemical and microbiological characterization of the water sample

\begin{tabular}{|c|c|c|c|}
\hline \multicolumn{2}{|l|}{ Physicochemical $^{\mathrm{a}}$} & \multicolumn{2}{|l|}{ Microbiological } \\
\hline Chlorides $\left(\mathrm{mg} \mathrm{l}^{-1} \mathrm{Cl}\right)$ & 20.0 & Enumerations $( \pm \mathrm{SD})$ & \\
\hline Conductivity, at $25^{\circ} \mathrm{C}\left(\mu \mathrm{S} \mathrm{cm}{ }^{-1}\right)$ & 338.0 & DAPI (total bacteria, cells $\mathrm{ml}^{-1}$ ) & $4.2 \times 10^{6} \pm 3.4 \times 10^{5}$ \\
\hline Colour (mg 1 $\left.{ }^{-1} \mathrm{Pt}-\mathrm{Co}\right)$ & 5.1 & R2A (total heterotrophs, CFU ml ${ }^{-1}$ ) & $2.5 \times 10^{3} \pm 6.1 \times 10^{2}$ \\
\hline Total hardness $\left(\mathrm{mg} \mathrm{l}^{-1} \mathrm{CaCO}_{3}\right)$ & 80.0 & PIA (Pseudomonas spp., CFU ml ${ }^{-1}$ ) & $5.7 \times 10^{2} \pm 4.6 \times 10^{1}$ \\
\hline Iron $\left(\mu \mathrm{g}^{-1} \mathrm{Fe}\right)$ & 121.0 & TTC (presumptive coliforms, CFU ml ${ }^{-1}$ ) & $1.4 \times 10^{2} \pm 3.5 \times 10^{1}$ \\
\hline Nitrates $\left(\mathrm{mg} \mathrm{l}^{-1} \mathrm{NO}_{3}^{-}\right)$ & $<5.0$ & & \\
\hline pH (Sorensen scale) & 7.8 & Cultivability $(\%)^{\mathrm{b}}$ & \\
\hline Total dissolved solids $\left(\mathrm{mg} \mathrm{l}^{-1}\right)$ & 220.0 & $\mathrm{R} 2 \mathrm{~A}$ & 0.059 \\
\hline Total suspended solids $\left(\mathrm{mg}^{-1}\right)$ & $<5.0$ & PIA & 0.014 \\
\hline Temperature in situ $\left({ }^{\circ} \mathrm{C}\right)$ & 26.1 & TTC & 0.003 \\
\hline Turbidity (NTU) & 1.7 & & \\
\hline
\end{tabular}

$\overline{D A P I}$ 4',6-diamidino-2-phenylindole, R2A R2A medium, PIA Pseudomonas Isolation Agar, TTC Tergitol 7-Agar, SD standard deviation

a These parameters were determined in the analytical laboratory of the water treatment plant, according to the recommendations of the drinking water directive (Council Directive 98/83/EC 1998)

b Cultivability was estimated as the ratio between the CFU ml ${ }^{-1}$ and the total number of cells ml ${ }^{-1}$ determined by DAPI staining

was determined as previously described (Lopes et al. 2011). Approximately $1.2 \mu \mathrm{g}$ of DNA were loaded onto a vertical polyacrylamide gel $(8 \% \mathrm{w} / \mathrm{v})$ with a denaturing gradient ranging from 29 to $59 \%$ (where $100 \%$ denaturing gradient is $7 \mathrm{M}$ urea and $40 \%$ deionized formamide) (DCode ${ }^{\mathrm{TM}}$ universal mutation detection system, Bio-Rad Laboratories, Munich, Germany) (Barreiros et al. 2008). DGGE gels were normalized using a ruler composed of a set of reference cultures that had a profile which covered the whole denaturing gradient in use. The DGGE profiles of the four DNA extracts were $100 \%$ concordant. Thus, one lane was selected for further analysis, with the excision and analysis of all bands as described before by Barreiros et al. (2011). For bands, sequencing analysis was used the InsTAclone ${ }^{\mathrm{TM}}$ PCR cloning kit (MBI Fermentas, Heidelberg, Germany), according to the manufacturer's instructions. DNA inserts of at least three different clones matching the original band in the DGGE pattern were sequenced with the primer M13F-pUC. Nucleotide sequencing and quality checking were performed as described previously (Barreiros et al. 2011).

\section{4 pyrosequencing}

One of the DNA extracts was used for 454 pyrosequencing. The 16S rRNA gene hypervariable V4-V5 region was amplified by PCR using the universal bacterial primers, 520F ( $5^{\prime}$-AYTGGGYDTAAAGN G-3') and 802R (5'-TACNVRRGTHTCTAATYC-3') (RDP's Pyrosequencing Pipeline: http://pyro.cme. msu.edu/pyro/help.jsp) fused to the $454 \mathrm{~A}$ and B adaptors, respectively. Standard PCR reaction conditions were employed for $50 \mu \mathrm{l}$ reactions with Fast Start polymerase (Roche, NJ, USA) - $1.8 \mathrm{mM} \mathrm{MgCl}_{2}$, $0.2 \mu \mathrm{M}$ each primer, $200 \mathrm{mM}$ dNTPs, $5 \mathrm{U}$ of polymerase and $2 \mu \mathrm{l}$ of template DNA. The PCR conditions were $94^{\circ} \mathrm{C}$ for $3 \mathrm{~min}$, followed by 30 cycles of $94^{\circ} \mathrm{C}$ for $30 \mathrm{~s}, 44^{\circ} \mathrm{C}$ for $45 \mathrm{~s}$ and $72^{\circ} \mathrm{C}$ for $60 \mathrm{~s}$ and a final elongation step at $72^{\circ} \mathrm{C}$ for $2 \mathrm{~min}$. The $16 \mathrm{~S}$ rRNA gene amplicon was sequenced on a 454 Genome Sequencer FLX platform according to standard 454 protocols (Roche-454 Life Sciences, NJ, USA).

Sequence analysis and phylogenetic classification

A cut-off value of $97 \%$ similarity of the $16 \mathrm{~S}$ rRNA gene sequences was considered to define an operational taxonomic unit (OTU). The 16S rRNA gene sequences obtained from culturable organisms (read lengths varying from 1357 to $1450 \mathrm{bp}$ ) and DGGE bands (read lengths varying from 164 to $203 \mathrm{bp}$ ) were aligned using Clustal W from MEGA 4.0 software (Tamura et al. 2007).

For 454 pyrosequencing, processing of sequencing reads and bacterial taxonomic identification were carried out through an in-house built pipeline 
(M. Pinheiro and A.C. Gomes, unpublished data). Raw sequencing reads were quality filtered according to the following criteria: (i) exact matches to primer sequences; (ii) sequences with less than two ambiguous bases (Ns), (iii) sequences longer than $100 \mathrm{bp}$, and (iv) longer sequences trimmed at $250 \mathrm{bp}$. The sequences were then aligned by making all-againstall possible pairwise sequence alignments with ClustalW, followed by building a pairwise-distance matrix with DNAdist program of the PHYLIP Package, v. 3.69 (Felsenstein 1993) and finally grouping of identical sequences into OTU (operational taxonomical units) at $97 \%$ similarity through MOTHUR (Schloss et al. 2009).

The taxonomical identity of each OTU was assigned through BLAST searches against the Ribosomal Database Project II (Cole et al. 2009), GenBank (www.ncbi.nlm.nih.gov) and SILVA (Pruesse et al. 2007). For dendrogram construction, 16S rRNA gene sequences of the type strain (Euzéby 1997) of the species observed to represent the closest neighbor of each OTU were included in the sequencebased comparative analysis. Dendrogram representations were obtained after pairwise and multiple sequence alignment on basis of the model of Jukes and Cantor (1969) and neighbor-joining method. The phylogeny inference method maximum parsimony was also applied to assess dendrogram reliability and stability. These analyses were performed with the software MEGA 4.0 (Tamura et al. 2007).

Richness, diversity and evenness indices

The diversity $\left[\mathrm{H}^{\prime}=-\Sigma p_{i} \ln \left(p_{i}\right)\right]$ and evenness $\left[\mathrm{J}=\mathrm{H}^{\prime} / \ln \left(\mathrm{H}_{\max }\right)\right]$ were measured using the Shannon's (Shannon and Weaver 1963) and Pielou's indices (Pielou 1966), respectively, calculated as described by Wang et al. (2008). The OTU, as defined above, was the basis for this calculation. For cultivable bacteria, the abundance of each OTU corresponded to the number of CFU per millilitre. For PCR-DGGE, the abundance of each OTU was estimated on basis of band intensity, measured with the aid of Bionumerics software package version 6.0 (Applied Math, Belgium). When a single band was observed to contain more than one OTU, an equitable distribution of the band intensity was considered. For pyrosequencing the abundance of each OTU corresponded to the number of sequences determined.
Non-identified bacteria were excluded from the calculations.

\section{Results}

Cultivable bacteria

Under the conditions used, cultivable bacteria ranged the $10^{2}-10^{3} \mathrm{CFU} \mathrm{ml}{ }^{-1}$ and total cells were about 1000 times more abundant. Cultivability ranged $0.003-0.059 \%$, with the lowest and highest values observed on TTC and R2A, respectively (Table 1).

In total, 39 bacterial strains were isolated-10 from TTC, 14 from PIA and 15 from R2A. Among these, two lost viability after isolation (1 from TTC and 1 from PIA), and four after freezing ( 2 from R2A, 1 from TTC and 1 from PIA). According to the 16S rRNA gene sequence analysis, TTC, PIA and R2A bacterial isolates were grouped into five, eight and eleven OTU respectively (Fig. 2a). This observation reflected a lower richness on the culture media TTC and PIA than on R2A and influenced the Shannon's diversity indices, also lower on the two selective culture media (Table 2). Presumably, such a selectivity led to the recovery of organisms of some bacterial genera not detected on R2A (Ralstonia, Chryseobacterium, Chitinophaga, Bacillus and Exiguobacterium on PIA, and Delftia and Lactococcus on TTC) (Fig. 2a). In total, cultivable bacteria were distributed by five phyla (Fig. 2b). Lower values of diversity and evenness indices were achieved using the culture-dependent survey, than when the cultureindependent methods were used (Table 2).

\section{Culture-independent methods}

DGGE analysis allowed the separation of 11 bands, seven corresponding to unique DNA sequences and four comprising a mixture of two or three DNA sequences. The OTUs identified through this method belonged to six phyla (Fig. 2b) and only about 50\% could be identified below the phylum level (orders Rickettsiales, 2.6\%; Sphingobacteriales, 9.7\%; Actinomycetales, 2.7\%; Chroococcales, $6.3 \%$ ). Three of the phyla identified by DGGE (Cyanobacteria, Planctomyces, Aquificae) were not represented among the cultivable bacteria, as expected due to the culture conditions used. 

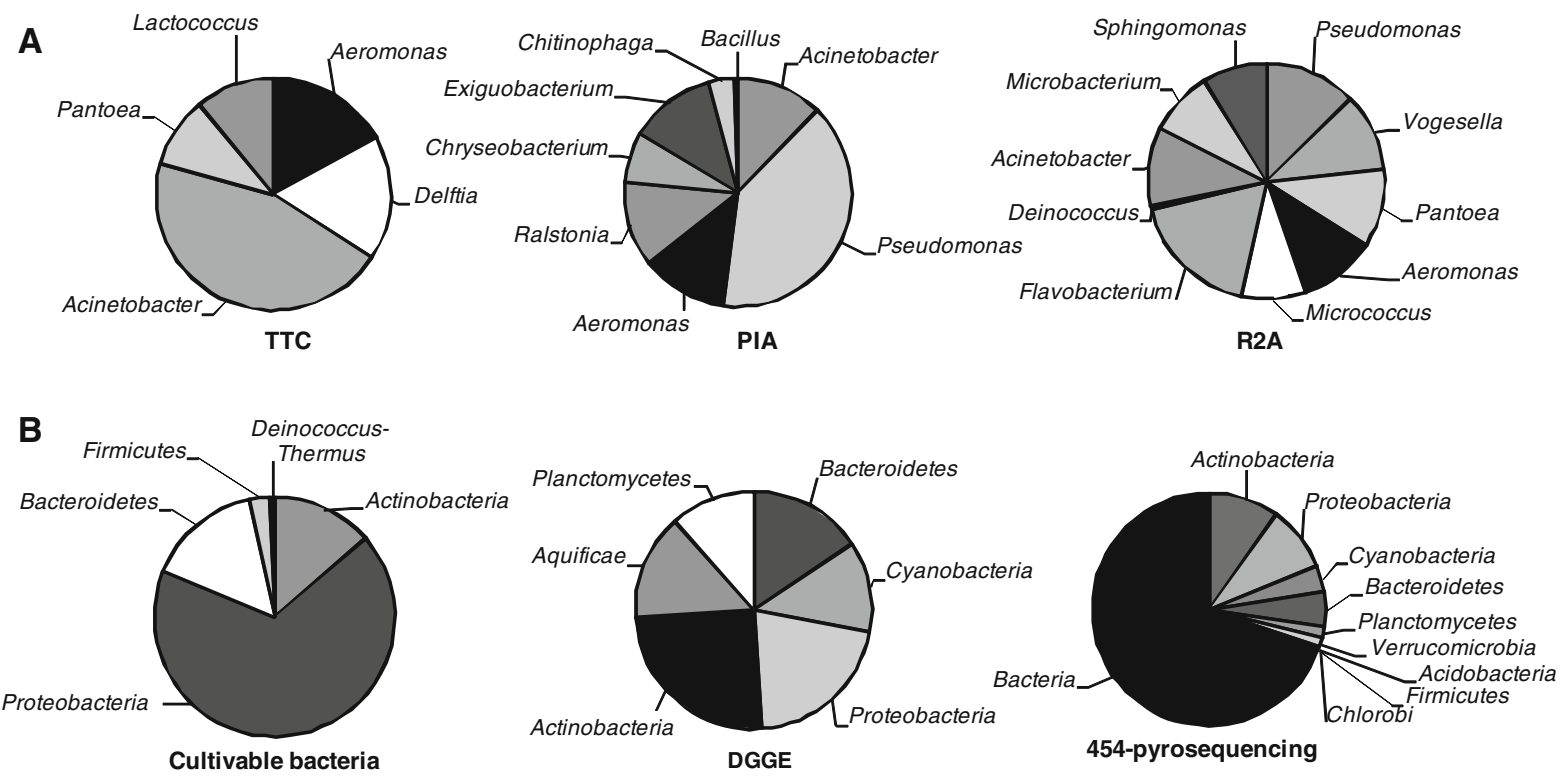

Fig. 2 a Bacterial diversity of the cultivable bacteria identified at the genus level, for the three different culture media; b Bacterial diversity at the phylum level obtained with each method used. Note: Percentages were estimated as the ratio between the: (i) the number of $\mathrm{CFU} \mathrm{ml}{ }^{-1}$ of each genus (a) or

Table 2 Shannon's diversity index (H') and Pielou's Evenness index $(\mathrm{J})$ for total and cultivable bacteria

\begin{tabular}{llllll}
\hline & \multicolumn{2}{l}{ Phylum } & & \multicolumn{2}{l}{ Genus } \\
\cline { 2 - 3 } \cline { 5 - 6 } \cline { 5 - 6 } & $\mathrm{H}^{\prime}$ & $\mathrm{J}$ & & $\mathrm{H}^{\prime}$ & $\mathrm{J}$ \\
\hline Cultivable bacteria & & & & \\
R2A & 0.93 & 0.12 & & 2.20 & 0.28 \\
PIA & 0.71 & 0.11 & & 1.73 & 0.27 \\
TTC & 0.35 & 0.07 & & 1.43 & 0.29 \\
PCR-DGGE & 1.75 & 0.24 & - & - \\
454 Pyrosequencing & $1.64^{\mathrm{a}}$ & $0.25^{\mathrm{a}}$ & - & - \\
\hline
\end{tabular}

${ }^{a}$ Unclassified bacteria (corresponding to $\mathrm{H}^{\prime}=0.26$ and $\mathbf{J}=0.03$ ) were excluded from this analysis

After quality control and filtering, 454 pyrosequencing analysis produced 2776 sequences with good quality (2302 from Bacteria, 28 from Eukarya and 446 "unknown"). The "unknown" sequences, which did not allow the identification to any validly named taxon, as well those identified as Eukarya, were excluded from the analysis. The resultant 2302 sequences identified as members of the domain Bacteria were grouped in 348 OTUs, corresponding to a value of bacterial diversity coverage of $62 \%$. The phylum (b) and the total number of $\mathrm{CFU} \mathrm{ml} \mathrm{m}^{-1}$, for cultivable bacteria; (ii) the intensity of each band and the sum of the intensity of all the bands, for DGGE; (iii) number of nucleotide sequence reads in each phylum and the total number of sequences, for 454 pyrosequencing

identification of OTU to at least the phylum level was possible to less than half of the consensus sequences (144 OTU), with 204 identified simply as Bacteria (Fig. 2b). In spite of the observed limitations, the 454 pyrosequencing allowed the identification of nine phyla, 18 orders (Sphingomonadales, Rhodobacterales, Rickettsiales, Burkholderiales, Neisseriales, Pseudomonadales, Legionellales, Chromatiales, Methylococcales, Pasteurellales, Bdellovibrionales, Sphingobacteriales, Flavobacteriales, Cytophagales, Nostocales, Actinomycetales, Solirubrobacterales and Verrucomicrobiales) and 14 genera (Legionella, Polynucleobacter, Acidovorax, Acinetobacter, Novosphingobium, Bdellovibrio, Vogesella, Flavobacterium, Rhodobacter, Conexibacter, Methylobacter, Haemophilus, Aphanizomenon and Caedibacter). Among the phyla detected by 454 pyrosequencing, but not by DGGE, were the Firmicutes, Chlorobi, Verrucomicrobia and Acidobacteria. In contrast, organisms most related to Aquificae were detected by DGGE analysis, but not by 454 pyrosequencing. Although the amount of DNA extract used for DGGE was higher than that used for 454 pyrosequencing, it is plausible to admit that this difference is related to 
the sensitivity or possible bias introduced by the PCR reaction in each method.

Culture-dependent versus DGGE or 454

pyrosequencing

Members of the phyla Proteobacteria, Actinobacteria and Bacteroidetes were observed to be predominant in this water sample, irrespective of the method used (Fig. 2). Nevertheless, when the 16S rRNA gene sequences of the bacterial isolates were compared with those retrieved by each of the methods used, it became clear that different OTUs were being targeted by each method (Figs. 3, 4). The most evident example of this fact was given by the OTUs of phylum Proteobacteria, which through the 16S rRNA gene sequence analysis of cultivable microorganisms comprised mainly Gammaproteobacteria $(73.2 \%)$ of the genera Pseudomonas, Acinetobacter, Aeromonas and Pantoea, through DGGE included the Alpha (42.9\%) and Gamma (27.6\%) classes, whereas pyrosequencing revealed the predominance of members of the classes Alpha (46.5\%) and Beta (37.2\%). Additionally, the comparison of 16S rRNA gene sequences of bacterial isolates with those of DGGE bands demonstrated that, even though members of the same phyla and classes were identified, rarely the sequences clustered together. Sequence similarities were lower than 93\%, indicating that both methods targeted a different set of organisms (Fig. 3).

The relatedness between the 16S rRNA gene sequences of the cultivable bacteria and through 454 pyrosequencing is shown in Fig. 4. As observed with DGGE, the 16S rRNA gene sequences from the cultivable bacteria tend to form distinct clusters of the sequences obtained by 454 pyrosequencing. However, in some cases it was possible to observe sequence similarity values higher than $97 \%$ (always lower than 98\%) (grey shadowing in Fig. 4; members of the family Commamonadaceae in the class Betaproteobacteria, of the genus Acinetobacter in the class Gammaproteobacteria and of the genus Flavobacterium in the phylum Bacteroidetes), suggesting that the same OTU could be detected by cultivation and by 454 pyrosequencing. Among the 454 pyrosequencing nucleotide sequences closely related $(>97 \%)$ with cultivable bacteria, only in one case it corresponded to a consensus construct (of 18 nucleotide sequences, 0BQ01AGUSG, within the phylum Bacteroidetes,
Fig. 4); all the others corresponded to single nucleotide sequences. This observation excluded the hypothesis that the clustering of sequences from bacterial isolates and from pyrosequencing could be due to the fact that consensus sequences were being used. These results evidence the higher bacterial diversity coverage of 454 pyrosequencing when compared with DGGE.

\section{Discussion}

The rates of cultivability observed confirm that only a small fraction of the bacterial population was recovered on the culture media used. Nevertheless, we admit the overestimation of the uncultivable fraction, given the fact that the method used to quantify the total number of cells (DAPI) neglects the organism viability (Kubista et al. 1987). Bacteria which rendered uncultivable could be injured organisms or members of taxa for which the growth conditions were not gathered. Supposedly, the culture-independent approaches would allow the detection of such taxa. The DGGE method allowed the detection of some taxa not cultivated, namely members of the phyla Cyanobacteria, Planctomyces and Aquificae. In some occasions it was observed the co-migration of DNA fragments with different nucleotide sequence compositions. This effect of co-migration was easily resolved through the analysis of different clones of a single band. Nevertheless, it is a major limitation of this method, mainly when the measurement of bacterial richness and/or diversity, relying on the number/intensity of bands, is the objective (Sekiguchi et al. 2001).

The 454 pyrosequencing analysis allowed the coverage of $62 \%$ of the predicted bacterial diversity, a value which was in the range of others observed for aquatic systems and can be considered representative of the phylotype richness (Kemp and Aller 2004). A prominent result of this analysis was the observation of high percentages of unclassified-bacteria. This fact may hint the huge bacterial diversity that presumably exists in a water sample and the potential of 454 pyrosequencing to detect rare organisms in microbial communities (Petrosino et al. 2009). But, most probably, these unknown Bacteria result from some drawbacks of this method, namely the occurrence of artifactual sequences and the limitations imposed by the short read lengths (Ahmadian et al. 2006; Krause et al. 2008; Warnecke and Hugenholtz 2007; Roh 
Fig. 3 Dendrogram constructed on basis of partial 16S rRNA gene sequences $(111 \mathrm{bp})$ of the cultivable bacteria (isolates identified with " $R$ " were isolated from R2A, "T" from TTC and "P" from PIA) and of the DGGE bands (marked in bold in the figure). Some related type species or closest described organisms were added to the dendrogram to validate the taxonomical identifications. The dendrogram was generated using the neighbour-joining method based on the model of Jukes and Cantor and the dark circles indicate branches recovered by the maximum parsimony method. Bootstrap values, generated from 1000 resamplings, at or above $50 \%$ are indicated at the branch points. Bar 1 substitution per $20 \mathrm{nt}$ positions

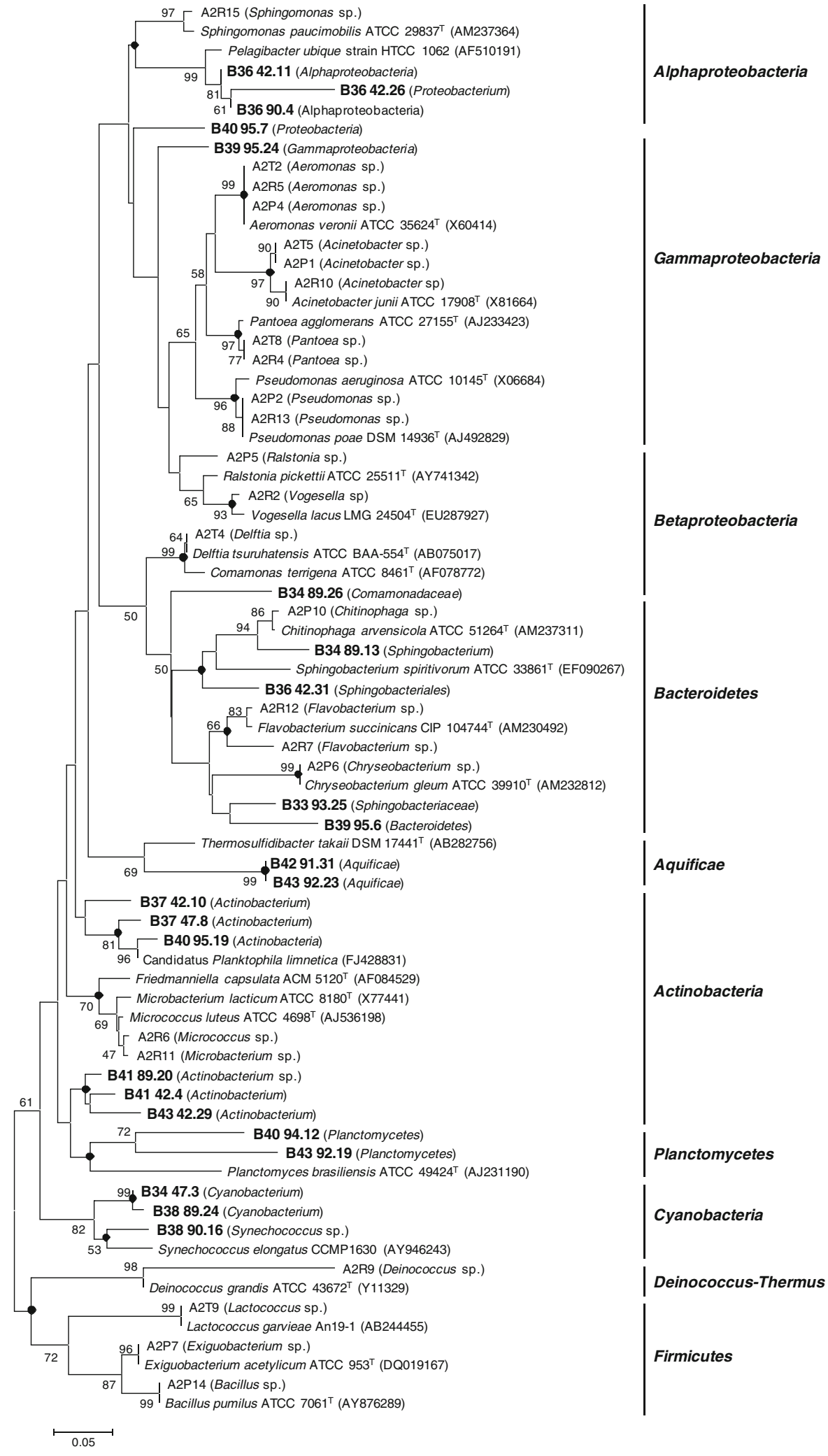


Fig. 4 Dendrogram constructed on basis of partial 16S rRNA gene sequences (205 bp) of the cultivable bacteria (isolates identified with " $R$ " were isolated from R2A, "T" from TTC and "P" from PIA) and the OTU obtained by 454 pyrosequencing. In order to validate the taxonomical identifications, the $16 \mathrm{~S}$ rRNA gene sequences of some of closely related type strains were added to the dendrogram. The dendrogram was generated using the neighbour-joining method based on the model of Jukes and Cantor and the dark circles indicate branches recovered by the maximum parsimony method. Bootstrap values, generated from 1000 resamplings, at or above $50 \%$ are indicated at the branch points. Grey shadowing indicates sequences retrieved from the different methods which share at least $97 \%$ similarity. Bar 1 substitution per $20 \mathrm{nt}$ positions

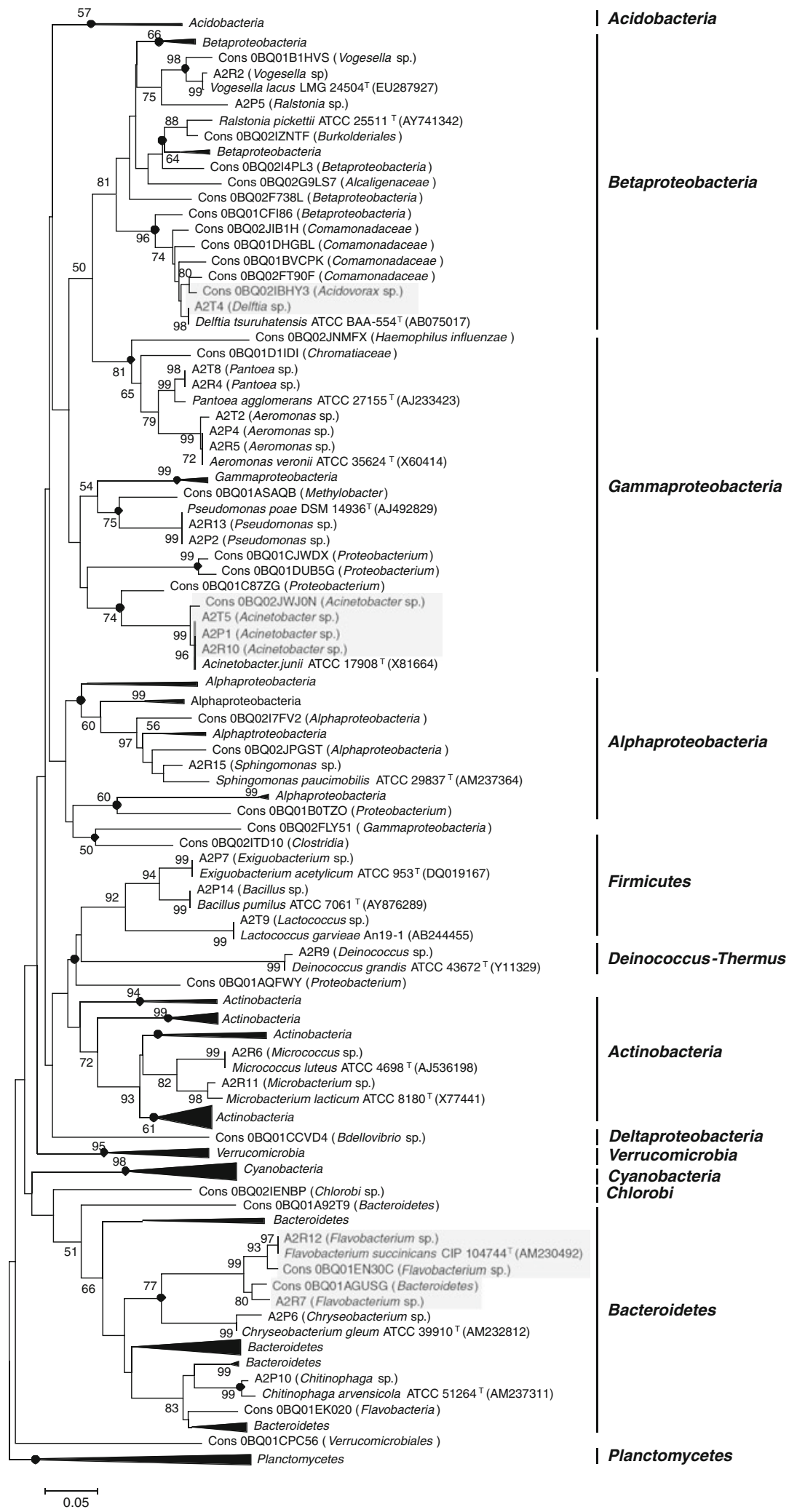


et al. 2010). These same drawbacks may be responsible for the lower diversity index value observed for 454 pyrosequencing when compared with the DGGE analysis (Table 2). Additionally, another possible bias introduced by this high throughput sequencing method is the preferential amplification of some DNA fragments. This effect may explain the low value of evenness observed for 454 pyrosequencing.

The predominant bacterial phyla in this water sample were Proteobacteria, Actinobacteria and Bacteroidetes, irrespective of the approach used. The members of these phyla are common inhabitants of freshwater, reported using either culture-dependent (high-throughput cultivation method, Gich et al. 2005), or culture-independent methods (16S rRNA based clonal analyses, Hiorns et al. 1997; Hugenholtz et al. 1998; Zwart et al. 2002; and metagenomic library and FISH analysis, Cottrell et al. 2005). Cyanobacteria, Planctomycetes and Verrucomicrobia, despite of being referred to as common freshwater bacteria (Zwart et al. 2002; Lindström et al. 2005), were, as expected, detected only through the culture-independent methods. Members of these groups or of others such as Acidobacteria, Aquificae and Deinococcus-Thermus hardly could be expected with the cultivation conditions used in the current study. Firmicutes were minor organisms both in the culture-dependent method and 454 pyrosequencing, suggesting the low abundance of members of this phylum in the sample, as pointed out before in other freshwater studies (Gich et al. 2005). At a lower taxonomic level, also some of the genera (Ralstonia, Flavobacterium, Chitinophaga, Micrococcus, Synechococcus) and families (Sphingobacteriaceae, Comamonadaceae, Legionellaceae) detected in this water sample were previously observed in freshwater using 16S rRNA clone libraries (Hiorns et al. 1997; Zwart et al. 2002), reverse line blot hybridization (Lindström et al. 2005) or metagenomic and FISH analysis (Cottrell et al. 2005).

The use of different primer sets for the DGGE and 454 pyrosequencing methods (V3 and V4-V5, respectively) was an attempt to compare the methods as they are more frequently used. However, this option limited a straightforward comparison of both culture-independent methods. Nevertheless, the major objective of this study was to infer if culturedependent and culture-independent methods currently used to survey freshwater microbiota coincided in the detection of cultivable bacteria. Supposedly, through the culture-dependent method only the most abundant organisms or the better adapted to the culture conditions were being screened. Bacterial strains examined in this study were in an abundance of about $10^{2}-10^{3} \mathrm{CFU} \mathrm{ml}{ }^{-1}$, which means that they were effectively isolated from volumes of water of $0.1-0.01 \mathrm{ml}$. Volumes higher than these corresponded to filtering membranes with "too much to count" CFU, from which bacterial isolation and purification would not be feasible. Through the culture-independent methods, for which total DNA was extracted from a higher volume of water (5000-50,000 times higher), we had anticipated that we would analyse a different fraction of the bacterial population. For this reason and due to the expected higher sensitivity, one would anticipate that the culture-independent methods may target the less abundant organisms. This justifies that some OTU not retrieved by culture-dependent methods were detected using the culture-independent approaches. Nevertheless, the most abundant organisms, namely those retrieved from volumes of $0.1-0.01 \mathrm{ml}$ of the water sample, were also expected to figure among the taxonomical units detected by the culture-independent methods, but, in fact, this only rarely occurred. A possible explanation is that some of the most abundant organisms (namely some detected by the culture-dependent methods) were probably lessened in favour of others occurring at lower densities, which may gain advantage during crucial stages as the DNA extraction and PCR amplification. This explains why DGGE and pyrosequencing failed to detect all or the majority of nucleotide sequences similar to those of the bacterial isolates. The 454 pyrosequencing, in spite its high coverage, allowed the detection of only four cultivable OTUs, always with sequence similarities lower than $98 \%$. The inability of the different methods to target the same organisms was previously observed (Kisand and Wikner 2003; Cottrell et al. 2005; Jordan et al. 2009). For instance, Kisand and Wikner (2003) observed that a culture-dependent method, a $16 \mathrm{~S}$ rRNA gene clone library and DGGE approaches allowed poor matches at species level for an estuarine bacterioplankton sample. Cottrell et al. (2005) through a metagenomic library approach detected some groups of bacteria underrepresented by a PCR$16 \mathrm{~S}$ rRNA gene clone library in a river water sample. 
Table 3 Qualitative analysis of cost-benefits for the three methods in study

\begin{tabular}{llll}
\hline & $\begin{array}{l}\text { Cultivable } \\
\text { bacteria }\end{array}$ & DGGE & $\begin{array}{l}454 \\
\text { Pyrosequencing }\end{array}$ \\
\hline $\begin{array}{l}\text { Cost } \\
\text { Time consumed }\end{array}$ & Medium & $\begin{array}{l}\text { High } \\
\text { Equipment }\end{array}$ & $\begin{array}{l}\text { Medium } \\
\text { Reagents }\end{array}$ \\
$\begin{array}{l}\text { Benefits } \\
\begin{array}{l}\text { Taxonomical } \\
\text { accuracy } \\
\text { (discriminative } \\
\text { power) }\end{array}\end{array}$ & Low & High & High \\
$\begin{array}{l}\text { Ease of performance } \\
\text { and interpretation }\end{array}$ & High & Low & Low \\
$\begin{array}{l}\text { Bacterial diversity } \\
\text { coverage }\end{array}$ & Low & Medium & Low \\
\hline
\end{tabular}

Also Jordan et al. (2009) in a study comparing the accuracy of pyrosequencing with culture dependent methods for the identification of isolates from blood culture bottles described that for some isolates no sequence match could be found, or the sequencing reactions repeatedly failed.

Ideally, both approaches, culture-dependent and independent, should be used as complementary, mainly if the objective of the study is related with risk assessment or public health issues. The choice on the culture-independent method to use is also relevant. If time consumption and costs involved versus information given are equated, the DGGE method does not show a worthy cost effectiveness (Table 3). In spite of these limitations DGGE is still regarded as an adequate approach to compare microbial communities and to infer the influence of environmental conditions (Fromin et al. 2002). The 454 pyrosequencing, although more expensive, presented high bacterial richness coverage and offered an efficient way to access the microbial diversity, namely to target some of the cultivable organisms. As a high-throughput approach, 454 pyrosequencing offers a general perspective of the microbial diversity and represent a valuable tool to develop and optimize cultivation methods. In fact, the latter are fundamental when phenotypic information is important, e.g. pathogenicity, antimicrobial resistance, production of novel metabolites and enzymes (Palleroni 1997; Alain and Querellou 2009).
Acknowledgments Authors gratefully acknowledge the workers from the water treatment plant for their kind collaboration on sample collection and for providing the physicochemical characterization of the water. This study was financed by Fundação para a Ciência e a Tecnologia (project PTDC/AMB/70825/2006 and IVM grant SFRH/BD/27978/ 2006).

Conflict of interest The authors declare that they have no conflict of interest.

\section{References}

Ahmadian A, Ehn M, Hober S (2006) Pyrosequencing: history, biochemistry and future. Clin Chim Acta 363:83-94

Alain K, Querellou J (2009) Cultivating the uncultured: limits, advances and future challenges. Extremophiles 13:583-594

Amann RI, Ludwig W, Schleifer K-H (1995) Phylogenetic identification and in situ detection of individual microbial cells without cultivation. Microbiol Rev 59(1):143-169

Amann RI, Fuchs BM, Behrens S (2001) The identification of microorganisms by fluorescence in situ hybridization. Curr Opin Biotechnol 12:231-236

Barreiros L, Fernandes A, Silva Ferreira AC, Pereira H, Bastos MMSM, Manaia CM, Nunes OC (2008) New insights into a bacterial metabolic and detoxifying association responsible for the mineralization of the thiocarbamate herbicide molinate. Microbiology 154:1038-1046

Barreiros L, Manaia CM, Nunes OC (2011) Bacterial diversity and bioaugmentation in floodwater of a paddy field in the presence of the herbicide molinate. Biodegradation 22(2):445-461

Bottari B, Ercolini D, Gatti M, Neviani E (2006) Application of FISH technology for microbiological analysis: current state and prospects. Appl Microbiol Biotechnol 73(3):485-494

Brunk C, Jones K, James T (1979) Assay for nanogram quantities of DNA in cellular homogenates. Anal Biochem 9:497-500

Cardenas E, Tiedje JM (2008) New tools for discovering and characterizing microbial diversity. Curr Opin Biotechnol 19:544-549

Cole JR, Wang Q, Cardenas E, Fish J, Chai B, Farris RJ, Kulam-Syed-Mohideen AS, McGarrell DM, Marsh T, Garrity GM, Tiedje JM (2009) The ribosomal database project: improved alignments and new tools for rRNA analysis. Nucleic Acids Res 37:D141-D145

Cottrell M, Waidner LA, Yu L, Kirchman DL (2005) Bacterial diversity of metagenomic and PCR libraries from the Delaware river. Environ Microbiol 7(12):1883-1895

de Figueiredo DR, Pereira MJ, Moura A, Silva L, Bárrios S, Fonseca F, Henriques I, Correia A (2007) Bacterial community composition over a dry winter in meso- and eutrophic Portuguese water bodies. FEMS Microbiol Ecol 59:638-650

Dewettinck T, Hulsbosch W, van Hege K, Top EM, Verstraete W (2001) Molecular fingerprinting of bacterial populations in groundwater and bottled mineral water. Appl Microbiol Biotechnol 57:412-418 
Eaton AD, Cresceri LS, Rice EW, Greenberg AB (2005) Standard methods for the examination of water and wastewater, 21st edn. American Public Health Association, Washington, DC

European Council (1998) Council Directive 98/83/EC of 3 November 1998 on the quality of water intended for human consumption as amended by regulation 1882/2003/ EC. Council of the European Union, Brussels

Euzéby JP (1997) List of bacterial names with standing in nomenclature: a folder available on the Internet. Int J Syst Bacteriol 47:590-592 (List of prokaryotic names with standing in nomenclature. Last full update March 09, 2011. http://www.bacterio.net)

Faria C, Vaz-Moreira I, Serapicos E, Nunes OC, Manaia CM (2009) Antibiotic resistance in coagulase negative staphylococci isolated from wastewater and drinking water. Sci Total Environ 407:3876-3882

Felsenstein J (1993) PHYLIP (phylogenetic inference package), version 3, 6th edn. Department of Genetics, University of Washington, Seattle

Ferreira da Silva M, Vaz-Moreira I, Gonzalez-Pajuelo M, Nunes OC, Manaia CM (2007) Antimicrobial resistance patterns in Enterobacteriaceae isolated from an urban wastewater treatment plant. FEMS Microbiol Ecol 60:166-176

Fromin N, Hamelin J, Tarnawski S, Roesti D, Jourdain-Miserez K, Forestier N, Teyssier-Cuvelle S, Gillet F, Aragno M, Rossi P (2002) Statistical analysis of denaturing gel electrophoresis (DGE) fingerprinting patterns. Environ Microbiol 4(11):634-643

Gich F, Schubert K, Bruns A, Hoffelner H, Overmann J (2005) Specific detection, isolation, and characterization of selected, previously uncultured members of the freshwater bacterioplankton community. Appl Environ Microbiol 71:5908-5919

Haack SK, Fogarty LR, West TG, Alm EW, McGuire JT, Long DT, Hyndman DW, Forney LJ (2004) Spatial and temporal changes in microbial community structure associated with recharge-influenced chemical gradients in a contaminated aquifer. Environ Microbiol 6(5):438-448

Hiorns WD, Methé BA, Nierzwicki-Bauer SA, Zehr JP (1997) Bacterial diversity in Adirondack mountain lakes as revealed by $16 \mathrm{~S}$ rRNA gene sequences. Appl Environ Microbiol 63(7):2957-2960

Hoefel D, Monis PT, Grooby WL, Andrews S, Saint CP (2005) Culture-independent techniques for rapid detection of bacteria associated with loss of chloramine residual in a drinking water system. Appl Environ Microbiol 71:6479-6488

Hong P-Y, Hwang C, Ling F, Andersen GL, LeChevalier MW, Liu W-T (2010) Pyrosequencing analysis of bacterial biofilm communities in water meters of a drinking water distribution system. Appl Environ Microbiol 76(16):5631-5635

Hugenholtz P (2002) Exploring prokaryotic diversity in the genomic era. Genome Biol 3(2):0003.1-0003.8 (reviews)

Hugenholtz P, Goebel BM, Pace NR (1998) Impact of cultureindependent studies on the emerging phylogenetic view of bacterial diversity. J Bacteriol 180:4765-4774

ISO 9308-1:2000, Water quality-detection and enumeration of E. coli and coliform bacteria. Part 1: membrane filtration method. International Organisation for Standardisation, Geneva, Switzerland
Jordan JA, Jones-Laughner J, Durso MB (2009) Utility of pyrosequencing in identifying bacteria directly from positive blood culture bottles. J Clin Microbiol 47(2):368-372

Jukes TH, Cantor CR (1969) Evolution of protein molecules. In: Munro HN (ed) Mammalian protein metabolism, vol 3. Academic Press, New York, pp 21-132

Kawai M, Matsutera E, Kanda H, Yamaguchi N, Tani K, Nasu M (2002) 16S ribossomal DNA-based analysis of bacterial diversity in purified water used in pharmaceutical manufacturing processes by PCR and denaturing gradient gel electrophoresis. Appl Environ Microbiol 68:699-704

Kemp PF, Aller JY (2004) Bacterial diversity in aquatic and other environments: what 16S rDNA libraries can tell us. FEMS Microbiol Ecol 47:161-177

Kisand V, Wikner J (2003) Combining culture-dependent andindependent methodologies for estimation of richness of estuarine bacterioplankton consuming riverine dissolved organic matter. Appl Environ Microbiol 69(6):3607-3616

Krause L, Diaz NN, Goesmann A, Kelley S, Nattkemper TW, Rohwer F, Edwards RA, Stoye J (2008) Phylogenetic classification of short environmental DNA fragments. Nucleic Acids Res 36(7):2230-2239

Kubista M, Akerman B, Nordén B (1987) Characterization of interaction between DNA and 4',6-diamidino-2-phenylindole by optical spectroscopy. Biochemistry 26:4545-4553

Lane DJ (1991) 16S/23S rRNA sequencing. In: Stackebrandt E, Goodfellow M (eds) Nucleic acid techniques in bacterial systematics. Wiley, Chichester, pp 115-175

Leclerc H (1994) Les eaux minerales naturelles: flore bactérienne native, nature et signification. Eaux Minérales 94:49-60

Leclerc H, Moreau A (2002) Microbiological safety of natural mineral water. FEMS Microbiol Rev 26(2):207-222

Lindström ES, Agterveld MPK-V, Zwart G (2005) Distribution of typical freshwater bacterial groups is associated with $\mathrm{pH}$, temperature, and lake water retention time. App Environ Microbiol 71:8201-8206

Lopes AR, Faria C, Prieto-Fernández A, Trasar-Cepeda C, Manaia CM, Nunes OC (2011) Comparative study of the microbial diversity of bulk paddy soil of two rice fields subjected to organic and conventional farming. Soil Biol Biochem 43(1):115-125

Loy A, Beisker W, Meier H (2005) Diversity of bacteria growing in mineral water after bottling. Appl Environ Microbiol 71(7):3624-3632

Manuel CM, Nunes OC, Melo LF (2007) Dynamics of drinking water biofilm in flow/non-flow conditions. Water Res 41(3):551-562

Mossel DAA, Struijk CB (2004) Assessment of the microbial integrity, sensu G.S. Wilson, of piped and bottled drinking water in the condition as ingested. Int $\mathbf{J}$ Food Microbiol 92:375-390

Murray AE, Hollibaught JT, Orrego C (1996) Phylogenetic compositions of bacterioplankton from two California estuaries compared by denaturing gradient gel electrophoresis of 16S rRNA fragments. Appl Environ Microbiol 62:2676-2680

Muyzer G, Smalla K (1998) Application of denaturing gradient gel electrophoresis (DGGE) and temperature gradient gel electrophoresis (TGGE) in microbial ecology. Antonie van Leeuwenhoek 73:127-141 
Muyzer G, de Waal EC, Uitterlinden AG (1993) Profiling of complex microbial populations by denaturing gradient gel electrophoresis analysis of polymerase chain reactionamplified genes encoding for 16S rRNA. Appl Environ Microbiol 59:695-700

Palleroni NJ (1997) Prokaryotic diversity and the importance of culturing. Antonie van Leeuwenhoek 72(3):3-19

Petrosino JF, Highlander S, Luna RA, Gibbs RA, Versalovic J (2009) Metagenomic pyrosequencing and microbial identification. Clin Chem 55(5):856-866

Pielou EC (1966) The measurement of diversity in different types of biological collections. J Theor Biol 13:131-144

Pruesse E, Quast C, Knittel K, Fuchs B, Ludwig W, Peplies J, Glöckner FO (2007) SILVA: a comprehensive online resource for quality checked and aligned ribosomal RNA sequence data compatible with ARB. Nucleic Acids Res 35(21):7188-7196

Revetta RP, Pemberton A, Lamendella R, Iker B, Santo Domingo JW (2010) Identification of bacterial populations in drinking water using $16 \mathrm{~S}$ rRNA-based sequence analyses. Water Res 44:1353-1360

Roh SW, Abell GCJ, Kim K-H, Nam Y-D, Bae J-W (2010) Comparing microarrays and next-generation sequencing technologies for microbial ecology research. Trends Biotechnol 28(6):291-299

Ronaghi M, Elahi E (2002) Pyrosequencing for microbial typing. J Chromatogr B Analyt Technol Biomed Life Sci 782:67-72

Schloss PD, Westcott SL, Ryabin T, Hall JR, Hartmann M, Hollister EB, Lesniewski RA, Oakley BB, Parks DH, Robinson CJ, Sahl JW, Stres B, Thallinger GG, Van Horn DJ, Weber CF (2009) Introducing mothur: open-source, platform-independent, community-supported software for describing and comparing microbial communities. Appl Environ Microbiol 75(23):7537-7541

Sekiguchi H, Tomioka N, Nakahara T, Uchiyama H (2001) A single band does not always represent a single bacterial strains in denaturing gradient gel electrophoresis analysis. Biotechnol Lett 23:1205-1208

Shannon CE, Weaver W (1963) The mathematical theory of communication. University of Illinois Press, Urbana

Tamura K, Dudley J, Nei M, Kumar S (2007) MEGA4: Molecular Evolutionary Genetics Analysis (MEGA) software version 4.0. Mol Biol Evol 24:1596-1599

Vartoukian SR, Palmer RM, Wade WG (2010) Strategies for culture of "unculturable" bacteria. FEMS Microbiol Lett 309:1-7

Venter JC, Remington K, Heidelberg JF, Halpern AL, Rusch D, Eisen JA, Wu DY, Paulsen I, Nelson KE, Nelson W et al (2004) Environmental genome shotgun sequencing of the Sargasso Sea. Science 304:66-74

Wang S-B, Li Q, Liang W-J, Jiang Y, Jiang S-W (2008) PCRDGGE analysis of nematode diversity in $\mathrm{Cu}$-contaminated soil. Pedosphere 18(5):621-627

Warnecke F, Hugenholtz P (2007) Building on basic metagenomics with complementary technologies. Genome Biol 8(12):231.1-231.5

Wu Q, Zhao X-H, Zhao S-Y (2006) Application of PCRDGGE in research of bacterial diversity in drinking water. Biomed Environ Sci 19:371-374

Zwart G, Crump BC, van Agterveld MP, Hagen F, Han S-K (2002) Typical freshwater bacteria: an analysis of available 16S rRNA gene sequences from plankton of lakes and rivers. Aquat Microb Ecol 28:141-155 